\title{
La salud como comunicación: medicina familiar y comunitaria
}

\author{
Eduardo Álvarez Pedrosian \\ Universidad de la República \\ (Montevideo, Uruguay)
}

\section{Palabra clave}

salud

comunicación

mediaciones

procesos de subjetivación

epistemología

medicina familiar y

comunitaria

\section{Resumen}

En este artículo se plantean algunas claves para comprender la relación intrínseca que puede existir entre salud y comunicación a partir de la perspectiva de la medicina familiar y comunitaria. Epistemológicamente se considera necesario reflexionar sobre dicho vínculo en el entendido de que generalmente se toman ambos conceptos de forma externa, lo que implica instrumentalizar la comunicación y simplificar el servicio ofrecido por los agentes sanitarios. A partir de la experiencia de creación y crecimiento de este tipo de medicina en el contexto de Uruguay, se plantea la presencia cercana aunque muchas veces poco evidente de la práctica médica generalista en la historia social de las poblaciones. Al considerar la atención en el primer nivel de salud como principal acti-vidad, la comunicación es valorada como una experiencia de encuentros entre subjetividades, y su gestión dialógica pasa a ser crucial para conceptualizar de otra manera la misma noción de salud. La comunicación en salud es abordada, por tanto, como un elemento sanitario más, al tiempo que la salud muestra su aspecto comunicacional desde el punto de vista de las dinámicas culturales y los procesos de subjetivación.

Este trabajo forma parte del proyecto "Las estrategias de información y comunicación centradas en los jóvenes y adolescentes en el ámbito de la salud: análisis y propuestas (Red de Atención Primaria, Administración de los Servicios de Salud del Estado, Zona 9 de Montevideo)", financiado por el Programa de Desarrollo Académico de la Información y la Comunicación (PRODICCSIC-UdelaR), Uruguay, 2010-2012. 


\section{Health as communication: family and community medicine}

\begin{tabular}{c}
\hline Keywords \\
\hline health \\
communication \\
mediation \\
family and community medicine \\
processes of subjectivation \\
epistemology
\end{tabular}

\section{Cómo citar el artículo}

Álvarez Pedrosian, E. (2013). La salud como comunicación: medicina familiar y comunitaria. Revista de Comunicación y Salud, 3(2), pp. 21-31.

DOI: http://doi.org/10.35669/revistadecomunicacionysalud.2013.3(2).21-31 


\section{Introducción}

Este ensayo surge a partir de ciertas consideraciones dentro de un proyecto de investigación más amplio, centrado en las estrategias de información y comunicación en el área de la salud elaboradas por parte de jóvenes y adolescentes en situación de vulnerabilidad socio-económica en una zona de Montevideo (Uruguay). Durante la realización del trabajo de campo etnográfico, resultó significativo encontrarnos con profesionales de la medicina operando en las policlínicas barriales de dicha zona que se inscribían en lo que se conoce como medicina familiar y comunitaria. Si bien existe una amplia bibliografía sobre la misma, nos encontramos ante la necesidad de elaborar una reflexión de corte epistemológico sobre la relación intrínseca que se establece entre los conceptos de comunicación, información y atención sanitaria.

Creemos que los vínculos son profundos, y la apelación a la comunicación no se reduce a una visión instrumental donde ya es definida y tomada en forma irreflexiva. Por el contrario, argumentamos que este tipo de medicina exige pensar la comunicación y la información de una forma crítica y creativa, lo que a su vez abre potencialidades innovadoras a la hora de considerar la forma en que se brindan los servicios sanitarios, desde la relación entre profesionales y pacientes a la forma de concebir las mediaciones y vínculos propios de toda forma de vida. Asimismo, la situación específica de la medicina familiar y comunitaria en el Uruguay, requiere una descripción particular que ponga en evidencia las condiciones y horizontes de posibilidad que caracterizan su presente y prefiguran su futuro cercano, más tomando en cuenta la actual situación de reforma del sistema sanitario en su totalidad, el llamado Sistema Nacional Integrado de Salud.

Los fenómenos que hemos investigado pueden expresarse, a trazo grueso y en términos comunicacionales, como una dialógica entre usuarios y operadores sanitarios. Si bien nuestro foco de interés es el joven y adolescente asistido, no podemos dejar de considerar las características que hacen al tipo de práctica médica específica en el vínculo con éste. Por eso es fundamental caracterizar los modelos y las prácticas de atención del cuerpo de médicos, auxiliares y otros profesionales asociados a la salud. Desde el punto de vista de los llamados estudios de la ciencia, se ha hecho énfasis en la necesidad de realizar el análisis en la constante remisión entre los aspectos tradicionalmente considerados como externos por un lado y como internos por el otro, como el contexto de la producción de conocimiento y como la forma lógica de sus enunciados respectivamente: "Los estudios sobre la ciencia pueden definirse como el proyecto cuya meta es eliminar por completo esta división... es una 'red sin costuras' que no puede desgarrarse en dos" (Latour, 2001: 105).

Investigaciones como esta, justamente, intentan poner en evidencia esa lógica articuladora en red: todo campo está constituido por flujos que conectan a otros campos, lo que implica en los términos de la teoría del conocimiento que todo saber está implícitamente cargado por las tensiones propias de las relaciones de fuerza existentes (Foucault, 1994). Un modelo asistencial, por tanto, no es una simple sumatoria de protocolos instrumentales sino que constituye una cristalización, siempre parcial y en tránsito, de un conjunto de prácticas llevadas a cabo de ciertas maneras específicas, 
donde está en juego la producción de subjetividad de todos los involucrados. Nuestra zona de exploración también se caracteriza por este tipo de abordaje, que encuentra en las policlínicas y en el mismo centro de salud los ámbitos de enseñanza, investigación y extensión universitaria más importantes del país, y desde donde se promueve el crecimiento de esta especialidad. Trataremos de esbozar sus aspectos importantes, en el entendido de que los fenómenos comunicacionales y el manejo de la información inherente a los mismos constituyen temáticas explícitamente consideradas desde esta perspectiva, lo que es de gran relevancia para comprender lo que acontece y poder proyectar insumos novedosos al respecto.

Los programas de investigación, más o menos paradigmatizados, más o menos hegemónicos o subalternos dentro de determinado campo y en sus ramificaciones (Bourdieu, 1999), son las matrices desde las cuales operan las prácticas concretas. Podríamos realizar un análisis sobre las relaciones entre lo que se dice, se postula, se define como información en las instancias comunicacionales específicas, y lo que sucede en la cotidianidad de la atención en las policlínicas barriales consideradas en el trabajo de campo. A nosotros nos interesa dedicarnos a lo segundo y profundizar allí en los vínculos con las subjetividades asistidas, dados los objetivos de la investigación. Pero considerando la necesidad de tomar en cuenta ambas dimensiones y sus relaciones, los discursos y las otras prácticas asociadas, es que reconocemos la existencia de un tipo de medicina practicada, con su propia historia, su configuración epistemológica y política en tanto que saber. Lo que resulta sumamente interesante, es el hecho de que la comunicación y la información no son elementos puramente externos a dicho saber, sino también internos, o siguiendo a Latour en el texto anteriormente citado (Latour, 2001), se trata del intercambiador entre ambas dimensiones continuas.

\section{Trazos de una historia cercana}

El "movimiento de la medicina familiar" tiene una genealogía por demás interesante. Turabián (1995: 3) recupera los trazos de dicha historia aparentemente ajena, pero tan cercana en los hechos a las poblaciones, configuradas tradicionalmente como comunidades y otros tipos de agregaciones sociales. Según su planteo, en el siglo XIX el médico general era la norma, mientras que a partir de la segunda mitad de siglo la ciencia positivista despliega un nuevo proceso, el de la especialización, que lleva a la medicina a condiciones de fragmentación y descontextualización en relación a las prácticas llevadas a cabo. Desde la década del sesenta del siglo XX, en Gran Bretaña, Australia, Canadá y Estados Unidos, comienza la reformulación de la "medicina general/ de familia". Por último, Turabián expone algunos aspectos que parecen fundamentales para comprender el tipo de red de problemáticas situadas que, como planteamos, cristalizan en un nuevo programa de investi-gación-intervención: "cambios en el patrón de morbi-mortalidad en las sociedades postindustriales, complejas interacciones de factores físicos, ambientales y comportamentales, como componentes etiológicos de los problemas de salud comunes, tendencia a privilegiar la atención primaria como elemento de cambio en los sistemas sanitarios para atender a las necesidades de la población". (Tu-rabián, 1995: 5). 
La sociedad uruguaya, compartiendo los rasgos demográficos latinoamericanos aunque acentuando ciertos aspectos que la caracterizaron como de las más europeizadas hasta hace unas décadas, es la última en incorporar la formación en medicina familiar y comunitaria como una especialidad. La propia Organización Panamericana de la Salud (OPS) lo había recomendado, desde que en 1987 comenzara a capacitar médicos generalistas, dándoles reconocimiento institucional a partir de la creación de un cargo de médico de familia en el órgano ministerial, así como aparece el primer programa docente focalizado en la comunidad junto a los primeros cargos para trabajar en él.

Como nos narran los galenos más involucrados en este proceso, entrevistados durante el trabajo de campo, la elección de la zona Nordeste del Departamento de Montevideo no fue para nada al azar. Esta era la experiencia desde la clínica pediátrica:

"Veíamos que en la internación, de cada 10 niños, 9 tenían desnutrición. Desnutrición severa. El mismo Doctor Mañé dijo en ese momento 'no puede ser, la clínica pediátrica tiene que trabajar en otro lado [pues estaba en el Hospital Materno-Infantil Pereira Rossell]. Tiene que irse para el primer nivel de atención'. Y ahí se empezó a buscar el lugar y cómo poder entrar con los estudiantes."

Es así que se escoge el barrio Jardines del Hipódromo, por el alto índice de mortalidad infantil por entonces (55 por 1.000 según los médicos entrevistados) y se pretende tener un acercamiento a los diversos territorios contiguos y desplegados a lo largo del eje Camino Maldonado Ruta 8 del Departamento Capitalino y el Área Metropolitana más en extenso.

En esta primera etapa del Centro de Salud Jardines del Hipódromo y su zona de influencia (1985-1988), el Dr. Mañé mantuvo contactos con las autoridades ministeriales para comenzar a intervenir conjuntamente con la formación y extensión universitaria. Dichos vínculos se vieron favorecidos por la presencia de otros actores sociales, siendo un emergente de este contexto la publicación de una revista de atención primaria en salud. El contexto específico de atención sanitaria en nuestra zona se vio, por tanto, enriquecido por la interdisciplinario del equipo conformado, la presencia de estudiantes integrando las funciones universitarias junto a dichos docentes, y la búsqueda de una articulación eficaz entre los diversos actores sociales involucrados. "Todos esos años y años, donde estaba pediatría, ginecología, salud mental y medicina preventiva, en forma no permanente... pero cuando las teníamos trabajábamos sensacional", manifiesta una de las profesionales entrevistadas.

Es, entonces, en el ejercicio de la atención pediátrica de primer nivel, desde donde comienza a ges-tarse la red de atención que conocemos en la actualidad. Pero ello se dio sobre el trasfondo y sin dejar de avanzar en la dirección de la medicina general, ampliando la cobertura a tipos de usuarios y situaciones más vastas. Según nos lo narraron las profesionales responsables de la formación y atención en la zona, los primeros médicos de familia de allí fueron capacitados a partir de sus especialidades generalistas, y como empresas unipersonales fueron instalando pequeñas policlínicas dependientes del centro de salud. Actualmente se denominan "médicos de área". Ese tipo de cobertura asistencial conllevaba sus complicaciones de gestión, 
remuneraciones diferenciales a la vez que gastos de funcionamiento específicos. No olvidemos también la presencia de policlínicas que dependían del gobierno municipal. La creciente presencia universitaria fue consolidando la aparición y expansión de otro modelo dentro del cual estas otras formas eran incorporadas.

Para el 2003 nos encontramos con un posgrado específico, en el mismo momento en que amplios sectores de la población tradicionalmente más desfavorecida sufría los efectos más destructivos de la crisis económica y social que caracterizó la implementación de las políticas neoliberales en la región. En el primer nivel de atención, lo más cercano que se pudiera de los vecinos y usuarios, en el contexto de sus vidas, en los campos de experiencia y hábitat propios de su cotidianeidad, se fue tejiendo esta red que tuvo al mismo tiempo que enfrentarse con la emergencia social (desempleo estructural en las familias, problemas de vivienda, alimentación, etc.).

La puesta en práctica de otro modelo asistencial no deja de ser un desafío permanente, frente a las fuerzas y tendencias presentes tanto en los campos de la atención, formación e investigación médica como en los ámbitos sociales y culturales propios de los habitantes, para los cuales la atención de la salud se concibe a partir de imaginarios colectivos igual de hegemónicos o subalternos. La tolerancia a la frustración es una necesidad imperiosa, ante la existencia de distancias a veces abismales entre lo que puede efectivamente realizarse y "los ideales de la participación comunitaria", al decir de una de las profesionales. Junto con ello, es evidente que el proceso de consolidación del campo académico, con la creación en 2007 de un departamento específico, sigue en aumento (Jones, Sosa Abella y Vignolo, 2008: 90).

\section{La gestión de los encuentros}

"El Modelo de Atención Integral implica colocar en el centro la satisfacción de las necesidades de salud de las personas y reordenar a los efectores, desde el esquema burocrático piramidal por niveles, desconectados entre sí en lo funcional, a un esquema de redes asistenciales, responsabilizándose por la atención de la salud de una comunidad.

La atención a la salud en el primer nivel adquiere un rol protagónico como responsable del abordaje integral de las familias y la comunidad, con una fuerte orientación preventiva. Esta atención concentra la complejidad socio-sanitaria, por cuanto le corresponde establecer la per-tinencia, oportunidad y tipo de intervención y/o derivación de la gran gama de problemas bio-lógicos, psicológicos y sociales que afectan a la población.

En el modelo descrito, la comunidad, sus redes y el primer nivel de atención, son el eje articulador del quehacer sanitario" (Barrios Lajuní y Rodríguez, 2007: 5).

Este tipo de modelos son los que operan como cajas de herramientas operativizadas en la cotidiani-dad de las prácticas asistenciales en la red de atención primaria del Nordeste montevideano, y desde allí se consolida una visión de la atención sanitaria que viene expandiéndose a toda la sociedad, ciertamente de forma muy lenta pero sostenida. Todo ello se lleva a cabo según dinámicas comunicacionales específicas, 
las cuales tienen en los campos de experiencia de atención en las policlínicas su dimensión más determinante. Dicho universo de mediaciones es analizado en otro lugar; aquí cabe relacionar ello con la configuración cognoscente que es resultado y opera en las nuevas síntesis dadas en las experiencias de quienes habitan estos campos. No podemos precisar si existe uno o múltiples, si hay diferencias radicales, en los núcleos programáticos (principios ontológicos, supuestos gnoseológicos, valores de variados aspectos desde los cuales se intenta ejercer el oficio), pero sí fue constatado en las diversas observaciones participantes realizadas en diferentes espacio-tiempos de la red asistencial, especialmente en las salas de espera de las policlínicas, así como fue profundizado gracias a entrevistas realizadas a quienes conforman el sistema asistencial, profesionales de variada índole, articulados en diversas redes más o menos institucionalizadas, encontrando en los médicos de familia y comunidad el vínculo con la enseñanza universitaria, la investigación y el relacionamiento del conocimiento con el medio. Todos ellos constituyen diferentes figuras de me-diadores, en el sentido de los flujos de información y comunicación. Más que traducir un sistema en palabras, son quienes hacen real un organismo colectivo, que no existiría de otro modo.

Nada mejor para ello que pensar lo social como organismo en cuanto tal, incluidos los equipos de trabajo. La integralidad a la que se hace mención en el texto precedente se la define por dos aspectos, siendo el segundo esta condición rizomática (Deleuze y Guattari, 1997) de una correcta cobertura, de una llegada satisfactoria en el tejido social. Y el primer sentido hace referencia directamente a ello, y sin reducir al paciente a la figura de individuo y este, a su vez, a la de un cuerpo fisiológico. El sujeto es él y sus circunstancias, parafraseando a Ortega y Gasset, y nada más evidente cuando se trata de la salud, física, mental y social. En tal sentido, la mirada clínica debe ser holística y situacional, sensible a considerar la especificidad del caso considerado: "The basic sciences provide basic information. The clinician must interpret the information in the light of experience and practice" (Fry, Gambrill y Smith, 1979: 244). Dicha salud, es concebida como un buen vivir, más que como una situación de perfectas armonías y equilibrios, con lo cual el carácter preventivo pasa a ser una suerte de búsqueda de un estado de salud permanente, manejo razonable de las dinámicas vitales de sujetos siempre concebidos como sociales, resultado y resultantes de los procesos inter y transsubjetivos que los atraviesan. La familia en un primer nivel, y la comunidad en el siguiente, se completan con lo social como la más genérica de las dimensiones. Esta visión sistémica también ha ido complejizándose frente a nuevos procesos de subjetivación donde las formaciones modernas han dejado de ser modelo.

Igualmente, el alcance territorial de las prácticas de atención primaria, del contacto cara a cara, del encuentro comunicativo entre especialista y habitante, es la instancia decisiva que lo define todo. Este aspecto, que podríamos calificar como de "experiencial", es decir, que toma en cuenta al campo de inmanencia de las puras prácticas como el del fundamento de lo que se piensa y hace en la asistencia, conlleva una potencia de integralidad, en el sentido en que se está interviniendo en una disposición propicia para la investigación científica, a la vez que se genera y transmite información y conocimiento.

Este poner a la comunicación en el sustento epistemológico, se nos presenta de manera más explícita en un entorno por demás significativo en relación al cartografiado 
de los procesos comunicacionales que se encuentran aquí en juego; se trata de los auxiliares de salud. Como parte del proceso de crecimiento de la especialidad en el contexto universitario y los impulsos en el sistema asistencial, se ha ido incorporando la formación de estos como manera de trabajar el nexo de la asistencia con el territorio desde la enseñanza en ambos roles, en el equipo (Vignolo, s/f).

Por consiguiente, la cuestión fundamental a la que arribamos es la forma en que es concebida y practicada dicha comunicación. Y allí nos encontramos con una suerte de tensión entre dos grandes paradigmas a escala civilizatoria, no sólo científica, uno que nos obliga a escoger entre lo disyuntivo y lo conjuntivo, entre analizar y sintetizar, desbrozar y volver a tejer, y otro que encuentra necesario considerar ambas tendencias en relaciones complejas de composición (Morin, 1992). Más específicamente, la cuestión es cómo se piensa dicha red, el carácter de lo relacional como sustento de una lógica particular puesta en práctica.

Si la atención primaria es constitutiva de la práctica de la medicina generalista, conocida como familiar y comunitaria, es porque encuentra en el vínculo entre médico y paciente la piedra de toque para valorar, evaluar y proyectar cualquier tipo de modelo asistencial, incluidas las estrategias de comunicación e información. La comunicación cara a cara establecida en los espacios de consulta, antes y después, pero también a veces durante las esperas, entendida como un encuentro, está explícitamente problematizada, por ejemplo en los términos de la "gestión de la incertidumbre" propia del espacio-tiempo de la consulta/diagnóstico: "Considerar a los seres humanos como procesadores perfectos de información no sólo es inadecuado, sino que es improbable que permita realizar un razonamiento eficiente e inteligente" (Turabián y Pérez Franco, 2006: 166). Es en ese diálogo plagado de incertidumbres a ser vehiculizadas que se hace salud; es la comunicación la que propicia la salud, previene y gestiona una buena vida (Sluzki, 1995). En este punto, la denominada "ecología de la comunicación" (Winkin, 1982; Bateson, 1991) converge inevitablemente con la medicina familiar y comunitaria, dados los intereses y propósitos que la motivan.

No necesariamente, pero sí en potencia, las nuevas tecnologías de la información y la comunicación pueden habilitar usos y aplicaciones que fomenten este tipo de prácticas. Las mismas también se encuentran en otras tramas, otras redes existentes, especialmente en los tradicionales contextos asociados a barrios y otros tipos de territorialidades. Estas redes, conocidas por la antropología clásicamente como de reciprocidades (Mauss, 1972), en diferentes niveles y estratos que van de mediaciones más directas a encadenamientos más extensos, tampoco están naturalmente dadas, son fenómenos históricos que se transforman y se reconoce en ellos diversas jerarquías y estratificaciones. Las dinámicas horizontales frente a la verticalidad de las formas disciplinarias modernas, o a lo sumo transversales entre los diferentes "planos de comunicación" (Peñaranda-Correa, 2011) habilitan nuevos márgenes de acción para explorar el desarrollo de una salud entramada en la vida de las poblaciones, pero ello no es para nada un proceso simple y automático, más bien todo lo contrario. El trabajo explícito sobre la información y la comunicación es, en tal sentido, una apuesta fundamental, aunque no suficiente, sí indispensable. 


\section{A modo de conclusión}

Un modelo asistencial sustentado en una medicina que se piensa desde los vínculos entre agentes sanitarios y la población, no hace uso de la información y la comunicación como instrumentos neu-tros, sino que las problematiza profundamente. Acepta los retos de los encuentros-desencuentros entre subjetividades, la complejidad de los medios y las mediaciones, las cualidades variables de los contenidos y formas de expresarlos, en una incesante búsqueda de participación y compromiso por parte de todos los involucrados. Para el caso del Uruguay, el proceso es reciente, y puede significar un cambio de perspectiva más que necesario para la democratización de los servicios de salud, fomentada a nivel abstracto desde el nuevo Sistema Integrado de Salud.

La comunicación, por tanto, no es solo una forma (instrumento) de llevar una información dada de un sitio al otro, de un emisor a un receptor pasivo, a lo sumo persuadido, según el esquema clásico, sino un tipo de práctica que genera contenidos propicios para fomentar la salud, una experiencia que produce subjetividad, es decir singular y singularizante en y desde lo vincular (Díaz y Uranga, 2011). El complejo de cualidades culturales, donde emergen con fuerza las relaciones de género y el rol de las mujeres en el cuidado familiar y colectivo en general (Ludueña, Olson y Pasco, 2005), así como los valores de tipo étnico, religioso y de corte generacional, no son elementos ajenos a la salud, sino constituyentes de la misma (Lê, 2006). Todo ello está siendo evidenciado por parte de quienes ejercen la medicina familiar y comunitaria en un contexto que aún sigue decantándose, en términos generales, hacia la ultra-especialización de un saber que aspira a la pura abstracción y la mercantilización del servicio.

\section{Referencias}

Barrios Lajuní, Anahí y Rodríguez, Verónica. (2007). El equipo de salud en el ámbito comunitario. Propuesta de discusión en el marco del proceso de regionalización. Tesis de especialidad inédita. Universidad de la República. Montevideo. Disponible en http:// www.medfamco.fmed.edu.uy/Archivos/monografias/MonografiaEquipSalAmbCom.pdf. Recuperado el 20 de diciembre de 2012.

Bateson, Gregory. (1991). Pasos hacia una ecología de la mente. Una aproximación revolucionaria a la autocomprensión del hombre. Buenos Aires: Planeta.

Bourdieu, Pierre. (1999). El campo científico. En Bourdieu, Pierre. Intelectuales, política y poder. Buenos Aires: Eudeba.

Deleuze, Gilles y Guattari, Félix. (1997). Mil mesetas. Capitalismo y esquizofrenia II. Valencia: Pretextos.

Díaz, Hernán y Uranga, Washington. (2011). Comunicación para la salud en clave cultural y comunitaria. Revista de Comunicación y Salud. Vol. 1, n 1, pp. 113-124. 
Foucault, Michel. (1994). Verdad y poder. En Foucault, Michel. Microfísica del poder. Barcelona: Planeta-Agostini.

Fry, John; Gambrill, Eric y Smith, Robert. (1979). Scientific Foundations of Family Medicine. Chicago: Year Book Medical Publishers.

Jones, Juan Manuel; Sosa Abella, Alicia y Vignolo, Julio C. (2008). Formación de especialistas en medicina familiar y comunitaria. Cuadernos del CES. № 3, pp. 89-105. Disponible en http://www.smu.org.uy/elsmu/organismos/ces/cuadernos/cuadernos3/ art7.pdf. Recuperado el 10 de noviembre de 2012.

Latour, Bruno. (2001). El flujo sanguíneo de la ciencia. Un ejemplo de la inteligencia científica de Joliot. En Latour, Bruno. La esperanza de Pandora. Ensayos sobre la realidad de los estudios de la ciencia. Barcelona: Gedisa.

Lê, Quynh. (2006). Cultural Meaning in Health Communication. The Australian and New Zealand Adolescent Health Conference. Disponible en http://www.caah.chw.edu. au/conference/papers/paper_08.pdf. Recuperado el 8 de agosto de 2012.

Ludueña, Alicia del Carmen; Olson, Joanne y Pasco, Alberta. (2005). Promoción de la salud y calidad de vida entre madres de preadolescentes. Una etnografía enfocada. Revista Latino-Americana de Enfermagem. Vol. 13, pp.1.127-1.134. Disponible en http://www.eerp.usp.br/rlae. Recuperado el 15 de noviembre de 2012.

Mauss, Marcel. (1972). Ensayo sobre el don. Forma y razón del intercambio en las sociedades arcaicas. En Mauss, Marcel. Antropología y sociología. Tecnos: Madrid.

Morin, Edgar. (1992). El pensamiento subyacente (paradigmatología). En Morin, Edgar. El método V. 4. Las ideas. Su hábitat, su vida, sus costumbres, su organización. Madrid: Cátedra.

Peñaranda-Correa, Fernando. (2011) Las fuerzas sociales y el escenario comunicativo en la educa-ción para la salud: el caso del programa de crecimiento y desarrollo. Ciência \& Saúde Coletiva. Vol. 16, $\mathrm{n}^{\circ}$ 10. Disponible en http://dx.doi.org/10.1590/ S1413-81232011001100007. Recuperado el 18 de julio de 2012.

Sluzki, Carlos. (1995). De cómo la red social afecta a la salud del individuo y la salud del individuo afecta a la red social. En Dabas, Elina y Najmanovich, Denise. (Coords.) Redes. El lenguaje de los vínculos. Hacia la reconstrucción y el fortalecimiento de la sociedad civil. Buenos Aires: Paidós.

Turabián, José Luis. (1995). Cuadernos de medicina de familia y comunitaria. Una introducción a los principios de medicina de familia. Madrid: Díaz de Santos.

Turabián, José Luis y Pérez Franco, Benjamín. (2006). El proceso por el cual los médicos de familia gestionan la incertidumbre: no todo son cebras y caballos. Atención 
Primaria. Vol. 38, n³, pp. 165-167. Disponible en http://www.elsevier.es/sites/default/ files/elsevier/pdf/27/27v38n03a13090982pdf001.pdf. Recuperado el 15 de noviembre de 2012.

Vignolo, Julio C. (s/f). Bienvenida a la página web de Departamento de Medicina Familiar y Comunitaria, Facultad de Medicina, Universidad de la República. Disponible en http://www.medfamco.fmed.edu.uy. Recuperado el 10 de julio de 2012.

Winkin, Yves. (1982). La nueva comunicación. Barcelona: Kairós. 